Gut and Liver, Vol. 11, No. 1, January 2017, pp. 142-148

\title{
Antireflux Metal Stent as a First-Line Metal Stent for Distal Malignant Biliary Obstruction: A Pilot Study
}

Tsuyoshi Hamada ${ }^{1}$, Hiroyuki Isayama ${ }^{1,2}$, Yousuke Nakai ${ }^{1}$, Osamu Togawa $^{1}$, Naminatsu Takahara ${ }^{1}$, Rie Uchino ${ }^{1}$, Suguru Mizuno $^{1}$, Dai Mohri ${ }^{1}$, Hiroshi Yagioka ${ }^{2}$, Hirofumi Kogure ${ }^{1}$, Saburo Matsubara ${ }^{1}$, Natsuyo Yamamoto ${ }^{1}$, Yukiko Ito $^{3}$, Minoru Tada $^{1}$, and Kazuhiko Koike ${ }^{1}$

'Department of Gastroenterology, Graduate School of Medicine, The University of Tokyo, ${ }^{2}$ Department of Gastroenterology, Tokyo Metropolitan Police Hospital, and ${ }^{3}$ Department of Gastroenterology, Japanese Red Cross Medical Center, Tokyo, Japan

Background/Aims: In distal malignant biliary obstruction, an antireflux metal stent (ARMS) with a funnel-shaped valve is effective as a reintervention for metal stent occlusion caused by reflux. This study sought to evaluate the feasibility of this ARMS as a first-line metal stent. Methods: Patients with nonresectable distal malignant biliary obstruction were identified between April and December 2014 at three Japanese tertiary centers. We retrospectively evaluated recurrent biliary obstruction and adverse events after ARMS placement. Results: In total, 20 consecutive patients were included. The most common cause of biliary obstruction was pancreatic cancer (75\%). Overall, recurrent biliary obstruction was observed in seven patients (35\%), with a median time to recurrent biliary obstruction of 246 days (range, 11 to 246 days). Stent occlusion occurred in five patients (25\%), the causes of which were sludge and food impaction in three and two patients, respectively. Stent migration occurred in two patients (10\%). The rate of adverse events associated with ARMS was 25\%: pancreatitis occurred in three patients, cholecystitis in one and liver abscess in one. No patients experienced nonocclusion cholangitis. Conclusions: The ARMS as a first-line biliary drainage procedure was feasible. Because the ARMS did not fully prevent stent dysfunction due to reflux, further investigation is warranted. (Gut Liver 2017;11:142-148)

Key Words: Antireflux; Biliary obstruction; Covered; Cholangiopancreatography, endoscopic retrograde; Metal stent

\section{INTRODUCTION}

Distal malignant biliary obstruction is a clinical entity which is caused mainly by pancreatobiliary cancers or a lymph node metastasis, and endoscopic placement of self-expandable metal stents (SEMS) is a well-established palliative treatment of nonresectable cases with longer patency time compared with plastic stents. ${ }^{1-4}$ A covered SEMS, which prevents the stent occlusion due to tumor ingrowth and epithelial hyperplasia through the mesh wall was developed, ${ }^{5-7}$ and the superiority of covered SEMS over uncovered SEMS in terms of stent patency has been reported particularly in pancreatic cancer cases. ${ }^{6,89}$ However, the occlusion of covered SEMS due to sludge or food impaction remains a serious problem to be addressed, and the reflux of duodenal contents into the SEMS, i.e., duodenobiliary reflux, is supposed to be a key contributor to this type of SEMS dysfunction when SEMS are placed across the papilla and sphincter function is compromised. ${ }^{10-12}$

To overcome the problems associated with duodenobiliary reflux, an antireflux metal stent (ARMS) with a valve to prevent the reflux at the distal end was developed, and several investigators have reported the effectiveness of ARMS for nonresectable distal malignant biliary obstruction. ${ }^{13-16}$ While the designs of antireflux valves in those studies were different, ARMS have been reported to successfully provide longer patency time with a lower rate of cholangitis, compared with conventional SEMS. We have used an ARMS with a funnel-shaped antireflux valve and have sought the effectiveness of the ARMS on patients who experienced covered SEMS occlusion due to the duodenobiliary reflux, ${ }^{15}$ and thus, were considered to be at a higher risk for recurrent occlusion of a subsequent SEMS. ${ }^{17-19}$ In our pilot study of 13 patients, we demonstrated that the ARMS provided a safe reintervention for covered SEMS occlusion due to sludge or food impaction and significantly longer patency time compared with the occluded SEMS in the same cohort. ${ }^{15}$

Based on the promising results of ARMS as a reintervention

Correspondence to: Hiroyuki Isayama

Department of Gastroenterology, Graduate School of Medicine, The University of Tokyo, 7-3-1 Hongo, Bunkyo-ku, Tokyo 113-8655, Japan

Tel: +81-3-3815-5411, Fax: +81-3-3814-0021, E-mail: isayama-tky@umin.ac.jp

Received on November 12, 2015. Revised on December 8, 2015. Accepted on January 12, 2016. Published online June 13, 2016 pISSN 1976-2283 eISSN 2005-1212 https://doi.org/10.5009/gnl15579

@ This is an Open Access article distributed under the terms of the Creative Commons Attribution Non-Commercial License (http://creativecommons.org/licenses/by-nc/4.0) which permits unrestricted non-commercial use, distribution, and reproduction in any medium, provided the original work is properly cited. 
for covered SEMS occlusion, we expanded the indication of this ARMS to a first-line SEMS for nonresectable distal malignant biliary obstruction. Use of ARMS for this indication can provoke sludge formation or increase the attachment of food residue at the valve portion. ${ }^{20}$ Therefore, the aim of this study was to evaluate the feasibility of ARMS for SEMS-naïve patients with nonresectable distal malignant biliary obstruction.

\section{MATERIALS AND METHODS}

\section{Study design}

This was a multicenter retrospective study of consecutive patients who received an ARMS as the initial SEMS for nonresectable distal malignant biliary obstruction at The University of Tokyo Hospital and two affiliated referral centers. The primary outcome of this study was causes of recurrent biliary obstruction after ARMS placement. The technical feasibility of the current ARMS was confirmed in our previous pilot study. ${ }^{15}$ The secondary outcomes included time to recurrent biliary obstruction (TRB0), rate of nonocclusion cholangitis, and adverse events. This study was approved by the ethical committee of each institution and was conducted in accordance with the Helsinki Declaration. Written informed consent for ARMS placement and use of clinical data was obtained from all patients before the procedures.

\section{Patients}

Patients who received an ARMS as the initial SEMS for distal malignant biliary obstruction were included. Distal malignant biliary obstruction was defined as a biliary stricture $\geq 2 \mathrm{~cm}$ from the bifurcation. When primary diseases were considered as nonresectable based on consultation to surgeons and anesthesiologists at each institution, the decision to place an ARMS was made. Patients were excluded if hilar biliary stricture or a history of biliary SEMS placement was present, expected survival time was $<3$ months or gastrointestinal anatomy had been surgically altered (e.g., Billroth-II and Roux-en-Y reconstructions). Patients were followed-up every 2 to 4 weeks on an outpatient basis, and biliary adverse events were evaluated based on clinical symptoms (fever, abdominal pain, and jaundice) and laboratory results. When biliary adverse events were suspected, abdominal radiograph, ultrasound and/or computerized tomography were performed. Patients were hospitalized when further examination and management were indicated.

\section{Design of ARMS}

The ARMS used in this study was a fully-covered SEMS with an antireflux mechanism which was commercially available during the study period in Japan and was manufactured based on the Niti-S ComVi-type SEMS (Taewoong Medical Inc., Gimpo, Korea) with an expanded polytetrafluoroethylene membrane sandwiched by two nitinol mesh layers. ${ }^{21}$ A 7-mm-long funnelshaped antireflux valve made of the same material was attached to the distal end, including four 5-mm-long longitudinal nitinol wires for anchorage of its shape (Fig. 1). This valve is designed to shrink in the duodenal lumen when retrograde pressure is enhanced and thereby prevent the reflux of duodenal contents into the biliary system, while ensuring the antegrade flow of bile. Two lengths were available during the study (60 and 80 $\mathrm{mm}$ ), and the diameter was $10 \mathrm{~mm}$. The delivery system is $9-\mathrm{F}$ in diameter.

The following adverse events were evaluated: pancreatitis, nonocclusion cholangitis, cholecystitis, and others (bleeding, ulceration, penetration, perforation, and so forth). These adverse events were categorized as early (within 30 days) and late (31 days or later).
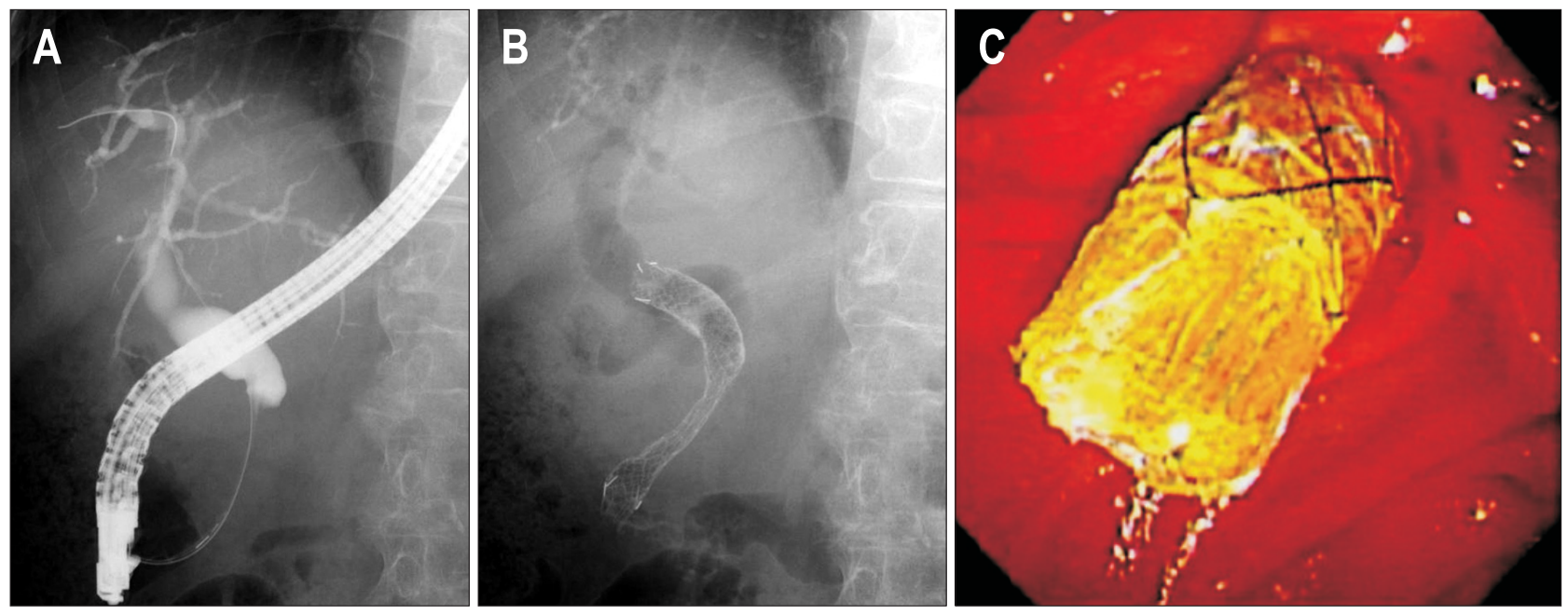

Fig. 1. Antireflux metal stent (ARMS) placement for distal malignant biliary obstruction. (A) Endoscopic retrograde cholangiography delineated distal biliary obstruction caused by pancreatic cancer. (B) An 8-cm-long, 10-mm-wide ARMS was successfully placed. (C) Endoscopic image showing a funnel-shaped antireflux valve attached to the distal stent end and bile flow into the duodenum. 


\section{Procedures}

Using standard endoscopic retrograde cholangiopancreatography techniques, ARMS were placed as described previously (Fig. 1). ${ }^{22,23}$ A side-viewing duodenoscope (TJF-260V; Olympus Medical, Tokyo, Japan) was inserted with moderate sedation. A plastic biliary stent, if present, was removed using a snare. Biliary access was obtained via wire-guided cannulation technique. ${ }^{24}$ After the location and length of biliary obstruction was confirmed by cholangiography, a 0.035-inch guidewire was passed through the stricture. The stent length (60 or $80 \mathrm{~mm}$ ) was determined according to the location of biliary obstruction along with the distance between the bifurcation and the duodenum. After sphincterotomy, the ARMS delivery system was advanced over the prepositioned guidewire, and the ARMS was deployed under fluoroscopic and endoscopic guidance with the distal end of the metal part being 5 to $10 \mathrm{~mm}$ in the duodenum.

\section{Definitions}

The outcomes of ARMS were defined and graded according to the Tokyo Criteria 2014. ${ }^{25}$ Briefly, stent occlusion was considered to be present if elevated liver enzymes compared with baseline values were observed along with biliary dilation on imaging studies or endoscopic findings, suggestive of stent occlusion. Causes of stent occlusion were determined based on findings of endoscopic reinterventions along with other imaging modalities. Stent migration was diagnosed when reintervention for ARMS dysfunction revealed a completely or partially migrated stent. Recurrent biliary obstruction was defined as a composite endpoint of either occlusion or migration, whichever came first, and the TRBO was the period from ARMS placement to recurrence of biliary obstruction. Patients who died without recurrent biliary obstruction were treated as censored cases at the time of death.

\section{Statistical analyses}

Using standard descriptive statistics, we documented the characteristics of the patients and ARMS. Continuous and categorical variables were expressed as medians with interquartile ranges (IQRs) or as numbers with percentages of patients, respectively. Survival time and TRBO were estimated using the Kaplan-Meier product-limit method. All analyses were performed using the JMP Pro software version 11.2.0 (SAS Institute, Cary, NC, USA).

\section{RESULTS}

\section{Patient characteristics}

The study population included a total of 20 consecutive patients who underwent ARMS placement as the initial SEMS for nonresectable distal malignant biliary obstruction between April and December 2014. The patient demographic profiles are
Table 1. Patient Characteristics $(n=20)$

\begin{tabular}{lc}
\multicolumn{1}{c}{ Characteristic } & Value \\
\hline Age, yr & $72(65-81)$ \\
Sex, male/female & $12 / 8(60 / 40)$ \\
Cause of biliary obstruction & $15(75)$ \\
$\quad$ Pancreatic cancer & $2(10)$ \\
$\quad$ Gallbladder cancer & $2(10)$ \\
Lymph node metastasis & $1(5)$ \\
$\quad$ Ampullary cancer & $35(25-46)$ \\
Primary tumor size, mm & $21(18-26)$ \\
Length of biliary stricture, mm & $10(50)$ \\
Distant metastasis & $7(35)$ \\
Duodenal tumor invasion & $11(55)$ \\
Chemotherapy after ARMS placement & $1.7(0.8-5.8)$ \\
Bilirubin, mg/dL & $5,300(4,050-6,400)$ \\
WBC count, / $\mu \mathrm{L}$ & $0.7(0.1-2.8)$ \\
CRP, mg/dL & \\
\hline
\end{tabular}

Data are presented as medians (interquartile range) or number (\%). ARMS, antireflux metal stent; WBC, white blood cell; CRP, C-reactive protein.

summarized in Table 1. The median age was 72 (IQR, 65 to 81) years, and the male to female ratio was 3:2. Pancreatic cancer was the predominant cause of biliary obstruction (75\%). Lymph node metastasis involving the distal bile duct was derived from gastric cancer and rectal cancer in one patient, each. Duodenal tumor invasion was present in seven patients (35\%). Four patients $(20 \%)$ received plastic biliary stent placement prior to ARMS placement with median duration time of 16 days (range, 4 to 41 days).

\section{Procedures of ARMS placement}

In all patients, an ARMS was deployed successfully via a single attempt for the intended location. Sphincterotomy was carried out in 15 patients (75\%) and in all of five patients with nonpancreatic cancer which was shown to be a risk factor for procedure-related pancreatitis. ${ }^{26}$ The lengths of the ARMS were $60 \mathrm{~mm}$ in four patients and $80 \mathrm{~mm}$ in 16. After ARMS deployment, endoscopic images confirmed appropriate expansion of the antireflux valve and bile flowing out of the stent in all cases.

\section{Outcomes of ARMS}

Table 2 summarizes the outcomes of ARMS for distal malignant biliary obstruction. The patients were followed until death or August 2015. During the follow-up period, 15 patients (75\%) died with a median survival time of 151 days (95\% confidence interval, 72 to 271) after ARMS placement. Overall, seven patients (35\%) experienced recurrent biliary obstruction, and the remaining died due to the progression of primary diseases 
Table 2. Outcomes of ARMS for Nonresectable Distal Malignant Biliary Obstruction $(\mathrm{n}=20)$

\begin{tabular}{lcc}
\hline & No. (\%) & Time to event, day \\
\hline Recurrent biliary obstruction & & \\
Occlusion & $5(25)$ & \\
$\quad$ Sludge & $3(15)$ & $11,97,246$ \\
$\quad$ Food impaction & $2(10)$ & 53,88 \\
Migration & $2(10)$ & \\
$\quad$ Distal & $1(5)$ & 194 \\
$\quad$ Proximal & $1(5)$ & 24 \\
Adverse events & & \\
Early adverse events $(\leq 30$ day) & & 1, each \\
$\quad$ Pancreatitis & $3(15)$ & 13 \\
$\quad$ Cholecystitis & $1(5)$ & 49 \\
Late adverse events $(\geq 31$ day) & & \\
$\quad$ Liver abscess & $1(5)$ & \\
\hline
\end{tabular}

ARMS, antireflux metal stent.

without ARMS dysfunction. The median TRBO was 246 days (range, 11 to 246) (Fig. 2). ARMS occlusion occurred in five patients (25\%); the causes of ARMS occlusion were sludge $(n=3)$ and food impaction $(n=2)$. ARMS migration occurred in two patients (10\%); the ARMS migrated distally and proximally in one patient, each. All dysfunctional ARMS were removed endoscopically using a snare, except proximally migrated one which was withdrawn using a biopsy forceps so that the distal end was located in the duodenal lumen, followed by removal using a snare.

\section{Adverse events associated with ARMS}

Overall, the rate of adverse events after ARMS placement was 20\%; early and late adverse events were observed in four (20\%) and one patients (5\%), respectively. All patients with pancreatitis were managed conservatively; mild and moderate in two and one patient, respectively. One patient developed cholecystitis on day 13, which was not amenable to conservative management and was managed by percutaneous cholecystostomy (graded as moderate). Another patient developed liver abscess on day 49, which required intravenous administration of antibiotics (graded as mild). ARMS removal was not required in any patients with adverse events. No patients experienced nonocclusion cholangitis.

\section{DISCUSSION}

This multicenter study demonstrated the feasibility of ARMS for nonresectable distal malignant biliary obstruction in 20 SEMS-naïve patients. Therein, the rate of recurrent biliary obstruction after ARMS placement was 35\% with an estimated median TRBO of 246 days. Given the fact that ARMS dysfunc-

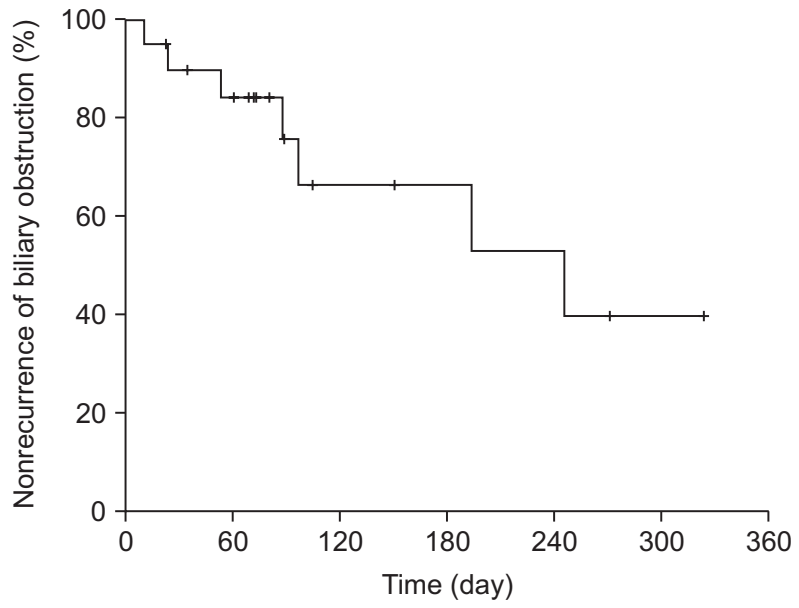

Fig. 2. Kaplan-Meier curve showing time to recurrent biliary obstruction in 20 patients who received antireflux metal stent placement for nonresectable distal malignant biliary obstruction. Small vertical bars on the graph indicate censored cases.

tion due to the reflux of food residue was observed in up to $10 \%$ patients, however, our study could not draw a definite conclusion on the superiority of ARMS over conventional covered SEMS in terms of stent patency. Therefore, a further investigation is required to validate the effectiveness of the present ARMS as a first-line SEMS.

Covered SEMS can prevent cancerous and hyperplastic tissue from invading through the mesh wall, potentially leading to longer patency time compared with uncovered SEMS. ${ }^{6,8,9}$ Although covered SEMS are prone to stent migration because of the covering membrane which inhibits SEMS from embedding into the biliary epithelium and tumor, ${ }^{8,27}$ antimigration systems (e.g., flared ends) in covered SEMS has contributed to the reduction of the risk of SEMS migration., ${ }^{9,28,29}$ Given these circumstances, the duodenobiliary reflux currently remains a main cause of the dysfunction of covered SEMS. In most patients, SEMS should be placed with the distal end in the duodenum to cover the biliary stricture sufficiently, ${ }^{30}$ leading to the loss of the sphincter function and the resultant free reflux of duodenal contents (food residue and duodenal juice) into the bile duct. ${ }^{10-12}$ The duodenobiliary reflux occasionally provokes SEMS occlusion due to sludge or food impaction and ascending cholangitis. $^{10}$

To mitigate the risk of SEMS dysfunction due to the duodenobiliary reflux, ARMS with various types of antireflux valves were developed (Table 3), ${ }^{13-16}$ and showed potential effectiveness in terms of the prolongation of SEMS patency time and the reduction of the frequency of cholangitis during the follow-up period. In a landmark randomized trial by Hu et al. $(n=112),{ }^{16}$ an ARMS with a nipple-shaped valve was associated with a significantly longer patency time compared with a conventional uncovered SEMS (13 months vs 10 months, $\mathrm{p}=0.04$ ) as well as a lower rate of cholangitis. In a more recent randomized trial by 
Table 3. Designs and Outcomes of ARMS as a First-Line Metal Stent for Nonresectable Distal Malignant Biliary Obstruction (Summary of the Literature)

\begin{tabular}{|c|c|c|c|c|c|}
\hline $\begin{array}{l}\text { Design of an antireflux valve } \\
\text { (author, publication year) }\end{array}$ & Study design & Type of ARMS & $\begin{array}{c}\text { No. of } \\
\text { patients }\end{array}$ & $\begin{array}{c}\text { Median } \\
\text { patency, mo }\end{array}$ & $\begin{array}{l}\text { Causes of recurrent } \\
\text { biliary obstruction, no (\%) }\end{array}$ \\
\hline $\begin{array}{l}\text { Hemisphere valve with a } \\
\text { cross-shaped outlet (Hu et al., 2011) }\end{array}$ & $\begin{array}{r}\text { Prospective, } \\
\text { single-arm }\end{array}$ & $\begin{array}{l}\text { Partially covered/ } \\
\text { uncovered, 20/3; } \\
\text { proximal end flared }\end{array}$ & 23 & 14 & $\begin{array}{l}\text { Migration, } 3 \text { (13); overgrowth, } 2 \text { (9); } \\
\text { ingrowth, } 1 \text { (4) }\end{array}$ \\
\hline S-type valve (Lee et al., 2013) ${ }^{14}$ & $\begin{array}{r}\text { Prospective, } \\
\text { single-arm }\end{array}$ & Uncovered, straight & 32 & 14 & $\begin{array}{l}\text { Sludge, } 6 \text { (19); ingrowth } 4 \text { (13); } \\
\text { migration } 1 \text { (3) }\end{array}$ \\
\hline $\begin{array}{l}\text { Wine glass-shaped valve } \\
\text { (Kim et al., 2013) }^{20}\end{array}$ & $\begin{array}{r}\text { Prospective, } \\
\text { single-arm }\end{array}$ & $\begin{array}{r}\text { Partially covered, } \\
\text { both ends flared }\end{array}$ & 5 & 1 & Sludge, 4 (80) \\
\hline $\begin{array}{l}\text { Nipple-shaped valve with a } \\
\text { cross-shaped outlet (Hu et al., 2014) }\end{array}$ & RCT & $\begin{array}{l}\text { Partially covered, } \\
\text { proximal end flared }\end{array}$ & 52 & 13 & $\begin{array}{l}\text { Migration, } 5 \text { (10); ingrowth, } 3 \text { (6); } \\
\text { sludge, } 2 \text { (4); overgrowth, } 1 \text { (2); } \\
\text { unknown, } 6 \text { (12) }\end{array}$ \\
\hline $\begin{array}{l}\text { Long windsock-shaped valve } \\
\text { (Lee et al., 2016) }^{31}\end{array}$ & $\mathrm{RCT}$ & $\begin{array}{l}\text { Partially covered, } \\
\text { proximal end flared }\end{array}$ & 39 & 14 & $\begin{array}{l}\text { Sludge, } 4 \text { (10); migration, } 3 \text { (8); } \\
\text { valve dysfunction, } 2 \text { (5); } \\
\text { tumor ingrowth, } 1 \text { (3); } \\
\text { hemobilia, } 1 \text { (3); unknown, } 1 \text { (3) }\end{array}$ \\
\hline Funnel-shaped valve (the current study) & $\begin{array}{l}\text { Retrospective, } \\
\text { single-arm }\end{array}$ & $\begin{array}{l}\text { Fully covered, } \\
\text { straight }\end{array}$ & 20 & 8 & $\begin{array}{l}\text { Sludge, } 3 \text { (15); food impaction, } 2 \text { (10); } \\
\text { migration, } 2 \text { (10) }\end{array}$ \\
\hline
\end{tabular}

ARMS, antireflux metal stent; RCT, randomized controlled trial.

Lee et al. $(\mathrm{n}=77))^{31}$ an ARMS with a windsock-shaped valve provided significantly longer patency time compared with conventional covered SEMS (14 months vs 7 months, $p=0.01$ ). Of note, barium meal examination after stent placement demonstrated a significantly lower rate of the duodenobiliary reflux in the ARMS group (8\% vs 100\%, p<0.01). Our previous pilot feasibility study on ARMS as used in the current study showed that the ARMS provided an effective reintervention for the occlusion of a prior conventional SEMS due to the duodenobiliary reflux. ${ }^{15}$ Given the role of the duodenobiliary reflux in the dysfunction of covered SEMS as described, we were motivated to investigate the effectiveness of our ARMS as the initial SEMS for nonresectable distal malignant biliary obstruction.

In the present study, recurrent biliary obstruction after ARMS placement occurred in one-third patients, and the median TRBO was 8 months. Given the prolonged patency time of covered SEMS in recent series, ${ }^{9,32,33}$ the outcomes of the present ARMS were not remarkable, although the definitions of SEMS patency were remarkably different between studies. ARMS occlusion due to sludge was observed in three patients (15\%). Sludge formation in the biliary system after SEMS placement is more or less inevitable as far as an endoprosthesis is implanted in the bile duct. Therefore, despite a legitimate concern on a potential adverse effect of ARMS on sludge formation, the current ARMS can be a first-line treatment option for distal malignant biliary obstruction. Meanwhile, we believe that a major advantage of ARMS would be to prevent the reflux of food particles into the SEMS. In the present study, however, 10\% patients experienced
ARMS occlusion due to food impaction, and hence, the reflux of food residue from the duodenum could not be prevented completely via the current antireflux system. The modification of the design of the antireflux valve might be required to improve the antireflux function of the current ARMS and deserves a further investigation.

As shown in our previous study, duodenal tumor invasion was associated with an increased risk of early SEMS dysfunction due to the duodenobiliary reflux enhanced by the stagnation of duodenal contents based on narrowing of the duodenum itself or impaired peristalsis. ${ }^{30}$ We also found that patients with an indwelling duodenal SEMS were predisposed to a further enhanced risk of SEMS dysfunction due to the duodenobiliary reflux. ${ }^{34}$ Furthermore, patients who experience SEMS occlusion due to the duodenobiliary reflux are at a high risk of SEMS dysfunction due to the same mechanism after successful reintervention. ${ }^{19,30}$ Therefore, although we failed to demonstrate the obvious effectiveness of the present ARMS as a first-line SEMS for nonresectable distal malignant biliary obstruction, patients with occlusion of a prior SEMS due to the duodenobiliary reflux remain good candidates for reintervention using an ARMS. The indication of ARMS as the initial biliary drainage for nonresectable distal malignant biliary obstruction requires further evidence.

Several limitations should be addressed in the present study. A small, single-arm retrospective study design was a major drawback of this study. Given the fact that stent dysfunction due to the reflux of food residue could not be prevented com- 
pletely, a well-powered prospective study is required before routine use of the current ARMS as a first-line metal stent for distal malignant biliary obstruction is justified. Therefore, we are conducting a randomized controlled trial on ARMS versus conventional ComVi (Taewoong Medical Inc.) stent (covered SEMS with the same structure except an antireflux valve) for nonresectable distal malignant biliary obstruction (clinical trial registration number: UMIN000014784).

In conclusion, a covered SEMS with a funnel-shaped antireflux valve for nonresectable distal malignant biliary obstruction, though technically feasible and safe, failed to prevent the duodenobiliary reflux after SEMS placement sufficiently. A further investigation is warranted on a routine use of the present ARMS as a means of a first-line biliary drainage for nonresectable distal malignant biliary obstruction.

\section{CONFLICTS OF INTEREST}

No potential conflict of interest relevant to this article was reported.

\section{ACKNOWLEDGEMENTS}

We gratefully acknowledge the assistance of Dr. Keiji Ogura, Tokyo Metropolitan Police Hospital and Dr. Ryou Nakata, Japanese Red Cross Medical Center.

\section{REFERENCES}

1. Davids PH, Groen AK, Rauws EA, Tytgat GN, Huibregtse K. Randomised trial of self-expanding metal stents versus polyethylene stents for distal malignant biliary obstruction. Lancet 1992;340: 1488-1492.

2. Knyrim K, Wagner HJ, Pausch J, Vakil N. A prospective, randomized, controlled trial of metal stents for malignant obstruction of the common bile duct. Endoscopy 1993;25:207-212.

3. Lammer J, Hausegger KA, Flückiger F, et al. Common bile duct obstruction due to malignancy: treatment with plastic versus metal stents. Radiology 1996;201:167-172.

4. Isayama H, Yasuda I, Ryozawa S, et al. Results of a Japanese multicenter, randomized trial of endoscopic stenting for nonresectable pancreatic head cancer (JM-test): covered Wallstent versus DoubleLayer stent. Dig Endosc 2011;23:310-315.

5. Isayama H, Komatsu Y, Tsujino T, et al. Polyurethane-covered metal stent for management of distal malignant biliary obstruction. Gastrointest Endosc 2002;55:366-370.

6. Isayama $\mathrm{H}$, Komatsu $\mathrm{Y}$, Tsujino $\mathrm{T}$, et al. A prospective randomised study of "covered" versus "uncovered" diamond stents for the management of distal malignant biliary obstruction. Gut 2004;53: 729-734.

7. Nakai Y, Isayama H, Komatsu Y, et al. Efficacy and safety of the covered Wallstent in patients with distal malignant biliary ob- struction. Gastrointest Endosc 2005;62:742-748.

8. Saleem A, Leggett CL, Murad MH, Baron TH. Meta-analysis of randomized trials comparing the patency of covered and uncovered self-expandable metal stents for palliation of distal malignant bile duct obstruction. Gastrointest Endosc 2011;74:321-327.e3.

9. Kitano M, Yamashita Y, Tanaka K, et al. Covered self-expandable metal stents with an anti-migration system improve patency duration without increased complications compared with uncovered stents for distal biliary obstruction caused by pancreatic carcinoma: a randomized multicenter trial. Am J Gastroenterol 2013;108:1713-1722.

10. Okamoto T, Fujioka S, Yanagisawa S, et al. Placement of a metallic stent across the main duodenal papilla may predispose to cholangitis. Gastrointest Endosc 2006;63:792-796.

11. Misra SP, Dwivedi M. Reflux of duodenal contents and cholangitis in patients undergoing self-expanding metal stent placement. Gastrointest Endosc 2009;70:317-321.

12. Wen F, Lu Z, Mao X, Liang H, Guo Q. Bridging across the ampulla with metal stents: evidences for intestinal bile reflux. Hepatogastroenterology 2013;60:1903-1905.

13. Hu B, Wang TT, Shi ZM, et al. A novel antireflux metal stent for the palliation of biliary malignancies: a pilot feasibility study (with video). Gastrointest Endosc 2011;73:143-148.

14. Lee KJ, Chung MJ, Park JY, et al. Clinical advantages of a metal stent with an S-shaped anti-reflux valve in malignant biliary obstruction. Dig Endosc 2013;25:308-312.

15. Hamada T, Isayama H, Nakai $Y$, et al. Novel antireflux covered metal stent for recurrent occlusion of biliary metal stents: a pilot study. Dig Endosc 2014;26:264-269.

16. Hu B, Wang TT, Wu J, Shi ZM, Gao DJ, Pan YM. Antireflux stents to reduce the risk of cholangitis in patients with malignant biliary strictures: a randomized trial. Endoscopy 2014;46:120-126.

17. Schmassmann A, von Gunten E, Knuchel J, Scheurer U, Fehr HF, Halter F. Wallstents versus plastic stents in malignant biliary obstruction: effects of stent patency of the first and second stent on patient compliance and survival. Am J Gastroenterol 1996;91:654659.

18. Ornellas LC, Stefanidis G, Chuttani R, Gelrud A, Kelleher TB, Pleskow DK. Covered Wallstents for palliation of malignant biliary obstruction: primary stent placement versus reintervention. Gastrointest Endosc 2009;70:676-683.

19. Togawa 0 , Isayama $\mathrm{H}$, Tsujino $\mathrm{T}$, et al. Management of dysfunctional covered self-expandable metallic stents in patients with malignant distal biliary obstruction. J Gastroenterol 2013;48:13001307.

20. Kim DU, Kwon CI, Kang DH, Ko KH, Hong SP. New antireflux selfexpandable metal stent for malignant lower biliary obstruction: in vitro and in vivo preliminary study. Dig Endosc 2013;25:60-66.

21. Isayama H, Kawabe T, Nakai Y, et al. Management of distal malignant biliary obstruction with the ComVi stent, a new covered metallic stent. Surg Endosc 2010;24:131-137.

22. Nakai $Y$, Isayama $H$, Togawa 0 , et al. New method of covered 
wallstents for distal malignant biliary obstruction to reduce early stent-related complications based on characteristics. Dig Endosc 2011;23:49-55.

23. Hamada T, Isayama H, Nakai Y, Kogure H, Yamamoto N, Koike K. Tips and troubleshooting for transpapillary metal stenting for distal malignant biliary obstruction. J Hepatobiliary Pancreat Sci 2014;21:E12-E18.

24. Nakai Y, Isayama H, Tsujino T, et al. Impact of introduction of wire-guided cannulation in therapeutic biliary endoscopic retrograde cholangiopancreatography. J Gastroenterol Hepatol 2011; 26:1552-1558.

25. Isayama H, Hamada T, Yasuda I, et al. TOKYO criteria 2014 for transpapillary biliary stenting. Dig Endosc 2015;27:259-264.

26. Kawakubo K, Isayama H, Nakai Y, et al. Risk factors for pancreatitis following transpapillary self-expandable metal stent placement. Surg Endosc 2012;26:771-776.

27. Almadi MA, Barkun AN, Martel M. No benefit of covered vs uncovered self-expandable metal stents in patients with malignant distal biliary obstruction: a meta-analysis. Clin Gastroenterol Hepatol 2013;11:27-37.e1.

28. Isayama $\mathrm{H}$, Mukai $\mathrm{T}$, Itoi $\mathrm{T}$, et al. Comparison of partially covered nitinol stents with partially covered stainless stents as a historical control in a multicenter study of distal malignant biliary obstruction: the WATCH study. Gastrointest Endosc 2012;76:84-92.

29. Moon SH, Kim MH, Park do H, et al. Modified fully covered self- expandable metal stents with antimigration features for benign pancreatic-duct strictures in advanced chronic pancreatitis, with a focus on the safety profile and reducing migration. Gastrointest Endosc 2010;72:86-91.

30. Hamada T, Isayama H, Nakai Y, et al. Duodenal invasion is a risk factor for the early dysfunction of biliary metal stents in unresectable pancreatic cancer. Gastrointest Endosc 2011;74:548-555.

31. Lee YN, Moon JH, Choi HJ, et al. Effectiveness of a newly designed antireflux valve metal stent to reduce duodenobiliary reflux in patients with unresectable distal malignant biliary obstruction: a randomized, controlled pilot study (with videos). Gastrointest Endosc 2016;83:404-412.

32. Telford JJ, Carr-Locke DL, Baron TH, et al. A randomized trial comparing uncovered and partially covered self-expandable metal stents in the palliation of distal malignant biliary obstruction. Gastrointest Endosc 2010;72:907-914.

33. Kullman E, Frozanpor F, Söderlund C, et al. Covered versus uncovered self-expandable nitinol stents in the palliative treatment of malignant distal biliary obstruction: results from a randomized, multicenter study. Gastrointest Endosc 2010;72:915-923.

34. Hamada T, Nakai Y, Isayama H, et al. Duodenal metal stent placement is a risk factor for biliary metal stent dysfunction: an analysis using a time-dependent covariate. Surg Endosc 2013;27:12431248. 